\title{
Orações relativas em línguas Karíb
}

\author{
Relative clauses in Cariban languages
}

Resumo: Este trabalho examina os diversos tipos de orações relativas descritas para línguas da família Karíb. O tipo mais importante é o que emprega formas verbais nominalizadas. Em muitas línguas, este é o único tipo existente. Exemplos de várias línguas são apresentados e discutidos. Em algumas delas, há orações relativas finitas, marcadas, em geral, por partículas relativizadoras. Exemplos dos vários subcasos são descritos e discutidos. Conclui-se que o primeiro tipo é mais antigo, já que é mais homogêneo na família e, também, caracterizado pela aposição das formas nominalizadas aos seus antecedentes. A aposição é um fenômeno mais geral do qual há muitos exemplos que envolvem formas nominalizadas não-verbais ou até substantivos monomorfêmicos. Como, além disso, não há uma classe de palavras (adjetivos) especializada em modificar substantivos, sugere-se que, nas línguas Karíb mais conservadoras, não existe modificação gramatical: tudo se faz através da aposição de substantivos (ou sintagmas nominais), iconicamente entendidos como co-referentes.

Palavras-chave: Línguas indígenas. Lingüística descritiva. Sintaxe. Modificação.

Abstract: This work examines the various types of relative clauses that have been described for languages of the Cariban family. The most important type is based on nominalized verb forms; in many languages, this is the only available mechanism. Examples from several languages are presented and discussed. In some languages, there are finite relative clauses, marked by relativizing particles; examples of several subcases are described and discussed. It is concluded that the former type is older, since it is more homogeneous in the family. This type is characterized by the apposition of the nominalized verb forms to the nouns that they modify. Apposition is a more general phenomenon, of which there are many examples involving other non-verbal nominalized forms, and even monomorphemic nouns. In addition, since there is no word class ('adjectives') specialized in modifying nouns, it is suggested that there is no grammatical modification: everything happens by means of the apposition of nouns (or noun phrases), iconically understood as coreferent.

Keywords: Indigenous languages. Descriptive linguistics. Syntax. Modification.

I Universidade de Leiden. Academia Real Holadesa de Artes e Ciências. Pesquisador. Leiden, Holanda (s.meira@let.leidenuniv.nl).

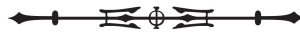




\section{INTRODUÇÃO'}

A familia Karíb compõe-se de cerca de 30 línguas faladas sobretudo ao norte do Amazonas, no Brasil, na Venezuela, na Colômbia e nas Guianas, mas com alguns membros mais ao sul, chegando até o Brasil central. Um quadro geral das línguas dessa família pode ser encontrado em Rodrigues (1986), Gildea (1998) e Derbyshire (1999).

Na familia Karíb, a estratégia relativizadora preponderante é o uso de nominalizações verbais, das quais há um bom número, em aposição ao termo relativizado. Em toda a familia, essa estratégia relativizadora é sempre freqüente; em muitas línguas, ela é a única estratégia possível. Na seção Nominalizações e relativas em Tiriyó, examinar-se-á em detalhe uma das línguas onde orações relativas são exclusivamente nominalizações: o Tiriyó. As nominalizações verbais do Tiriyó serão descritas e seu uso como relativas será exemplificado. Na seção Nominalização e Relativas em outras línguas Karíb, exemplos de outras línguas restritas a relativas nominalizadas serão apresentados de modo a mostrar que o padrão do Tiriyó é, de fato, freqüente na familia.

Há, contudo, um certo número de línguas que desenvolveram morfemas relativizadores, os quais podem ser usados para transformar uma oração normal, com verbo finito, não nominalizado, em uma oração relativa. Esta estratégia é encontrada sobretudo em línguas da área Venezuela-Guiana-Roraima, onde há com o uso de nominalizações. A seção Relativas não-nominalizadas apresentará exemplos de morfemas relativizadores das línguas Tamanaku, Panare e Yukpa, faladas na Venezuela. Nota-se que há diferenças notáveis entre o relativizador Yukpa e os morfemas correspondentes em Panare e Tamanaku, o que sugere que se trate de inovações independentes.

$\mathrm{Na}$ conclusão, serão comparados os padrões discutidos nas seções anteriores de um ponto de vista tipológico. Sugerir-se-á que os morfemas relativizadores são inovações recentes: o seu comportamento, nas línguas onde ocorrem, não é tão homogêneo quanto o das nominalizações. Em Panare, parece haver também uma possível fonte etimológica para os relativizadores, representados pelos pronomes demonstrativos e interrogativos.

\section{NOMINALZAÇÕES E RELATIVAS EM TIRIYÓ}

Em Tiriyó, uma língua típica da familia Karíb, a nominalização é um fenômeno bastante regular. Com exceção das partículas, todas as classes não-nominais (verbos, advérbios/adjetivos, posposições) podem ser nominalizadas.

Os verbos apresentam um sistema de nominalizações bastante rico. Há afixos específicos para derivar termos para os dois argumentos dos verbos transitivos (A 'agente', P 'paciente'), bem como para o argumento dos verbos intransitivos (S). Como os afixos são diferentes, é possível distinguir claramente verbos transitivos de verbos intransitivos. As nominalizações de argumentos apresentam duas formas: uma dita real, que descreve um participante de um evento específico (um cão que mordeu alguém; 1a, 1b e 1g), e uma dita potencial, que se refere a um participante de um evento possível (um cão que morde, capaz de morder, 1c, 1d e 1g).

1 Para facilitar a leitura, todos os exemplos em línguas Karíb foram retranscritos com o alfabeto fonético internacional (AFI); as vírgulas representam pequenas pausas.

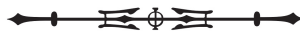


Além destas formas, há também nominalizações de circunstância (com idéia geral de propósito: um lugar, momento ou instrumento para a realização de algo) e de evento/ação (1e e 1h)2.

(1) Nominalizações verbais.

eta 'ouvir' (transitivo)

a. eta-ne 'aquele que ouve algo'

b. n-eta 'aquilo que é ouvido por alguém'

c. əta-ton 'aquele que ouve, é capaz de ouvir'

d. t-əta-en 'aquilo que se pode/deve ouvir'

e. eta-to 'lugar, momento, instrumento para ouvir' epi 'tomar banho' (intransitivo)

f. epi-ke 'aquele que

toma banho'

g. t-e:pə-en 'aquele que vai

tomar banho'

h. epi-to 'instrumento, momento, lugar para tomar banho'

Em seguida, podem ser vistos alguns exemplos do uso de formas verbais nominalizadas como orações relativas, referentes a A, (2a) e (2b); P, (2c) e (2d); S (2e); e a uma circunstância (2f). Note-se a diferença semântica entre nominalizações reais, (2a) e (2c), e potenciais, (2b) e (2d). Marcas de passado nominal (-mpə, -hp» 'ex-': por exemplo maja 'faca', maja-mpə 'ex-faca', 'aquilo que era uma faca') são usadas para indicar o tempo da ação da relativa. Observe-se nos exemplos (2a) e (2c) que o participante não relativizado ocorre como possuidor do verbo nominalizado, com o qual forma um sintagma nominal possessivo, indicado pelos colchetes (compare-se (2a) com pahko i-maja 'a faca do meu pai', um sintagma nominal possessivo típico, com a ordem possuidor-possuído e um prefixo de terceira pessoa $i$ - no item possuído).

(2) Nominalizações como orações relativas.

a. ampo nai, witoto, [kaikui i-tuika-ne-mpə] ?

onde 3.cop pessoa cachorro 3-bater-A.RE-NPAS

'Onde está a pessoa que bateu no cachorro?'

b. a:no nai, kaikui, əxka-ton ?

qual 3.COP cachorro morder-A.POT

'Qual é o cachorro que morde (=é selvagem, agressivo)?'

c. kaikui ə-wa:r, [pahko i-n-tu:ka-hpə] ?

cachorro 2-conhecido 1.pai 3-P.RE-bater-NPAS

'Você conhece o cachorro em que meu pai bateu?'

d. serə nai, eperu, t-əna-sen

DEM 3.COP fruta P.POT-comer-P.POT

'Este é o fruto que se come (= que se pode comer; comestível).'

2 Em Tiriyó, o nominalizador -to(po) funciona também como um nominalizador de evento/ação; 1 e e 1 g podem significar 'o fato de A ouvir P', 'o fato de s tomar banho'. Isso não ocorre, em geral, com outras línguas da família. Há outros nominalizadores de evento/ação: - $\emptyset$ 'ação específica' (com todos os verbos), -nə 'ação não-específica' (só com verbos intransitivos). Como as nominalizações resultantes não são usadas como 'orações' relativas, elas não serão discutidas neste trabalho.

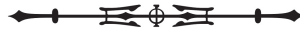


e. n-e:-jan witoto, epi-keti-mpə

3s-vir-PRES PesSOa tomar.banho-S.RE-NPAS

'Está vindo a pessoa que tomou banho.'

f. ampo nai, pakoro, ə-wərnih-topo-mpə ?

onde 3.cop casa 2-dormir-CIRC-NPAS

'Onde fica a casa em que você dormiu?'

Note-se que as nominalizações ocorrem em aposição ao termo relativizado: compare-se (2) com os exemplos de (3a) até (3d), em que dois substantivos co-referenciais ocorrem em aposição. Os termos em questão podem ser contíguos ( $3 a$ ) ou não-contíguos (3b), o que também é verdade no caso das nominalizações, conforme pode ser visto na comparação entre witoto e pahko i-tu:ka-ne-mpə, adjacentes em (2a), com kaikui e pahko i-n-tu:ka-hpo, não-adjacentes em (2c). Os exemplos (3e) e (3f) apresentam adicionais: o termo relativizado é objeto de um verbo transitivo $(P)$ e o verbo nominalizado que o modifica pode ser contíguo (3e) ou não (3f).

(3) Exemplos de mobilidade de termos em aposição.

$\begin{array}{lll}\text { a. wəri, } & \text { karaiwa, } & \text { ə-wa:rə ? } \\ \text { mulher não.índio } & \text { 2-conhecido }\end{array}$

'Você conhece a mulher, a branca?'

c. ə-pawana w-ene, tarəno

2-amigo 1A-ver.pAs Tiriyó

'Eu vi o seu amigo, o Tiriyó.'

e. maja w-ene,

livro 1A-ver.PAS

ə-ni-ri-hpə

'Eu vi a faca que você fez.'
b. wəri, ə-wairə, karaiwa ?
mulher 2-conhecido não.índio

'Você conhece a mulher, a branca?'
d. ə-pawana, tarono, w-ene 2-amigo Tiriyó 1A-ver.PAS

'Eu vi o seu amigo, o Tiriyó.'

f. maja, ə-ni-ri-hpə, w-ene faca 2-P.RE-fazer-NPAS 1A-ver.PAS

'Eu vi a faca que você fez.'

Também com posposições, o comportamento dos verbos nominalizados relativos é paralelo ao de substantivos em aposição. Em geral, os termos são não-contíguos e a posposição é repetida (4a). Nos casos em que os termos são contíguos, a melhor solução é repetir a posposição (4b), mas também é possível utilizá-la uma só vez, após o segundo termo (4c). Verbos nominalizados relativos seguem o mesmo padrão, como visto em (4d) e (4f).

(4) Exemplos de termos em aposição com a posposição pə(kə) 'sobre, a respeito de'.

a. wəri pə n-əturu, karaiwa pə mulher sobre 3s-falar.PAs não.índio sobre

'Ele falou sobre a mulher, a branca.'

b. wəri pə, karaiwa pə, n-əturu mulher sobre não.índio sobre 3s-falar.PAs

'Ele falou sobre a mulher, a branca.'

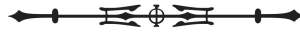


c. wəri karaiwa pə n-əturu mulher não.índio sobre 3s-falar.PAs 'Ele falou sobre a mulher, a branca.'

d. wəri pə n-əturu, j-ene-ne-mpə pə mulher sobre 3s-falar.PAS 1-ver-A.RE-NPAS sobre 'Ele falou sobre a mulher, a que me viu.'

e. wəri pə, j-ene-ne-mpə pə, n-əturu mulher sobre 1-ver-A.RE-NPAS sobre, 3s-falar.PAS 'Ele falou sobre a mulher, a que me viu.'

f. wəri j-ene-ne-mpə pə, n-əturu

mulher 1-ver-A.RE-NPAS sobre 3s-falar.PAS

'Ele falou sobre a mulher, a que me viu.'

As nominalizações discutidas anteriormente referem-se aos participantes principais (A, P, S). Não existe uma nominalização específica para participantes dativos (recipientes); estes não podem, conseqüentemente, ser 'relativizados'. É, contudo, possível derivar um verbo benefactivo com o sufixo -ntə 'prover de' a partir de uma raiz nominal, o qual toma o recipiente como seu objeto direto; por exepmlo, kewei 'anzol', kewei-ntə 'dar um anzol a P', 'prover P de anzol'. Trata-se de um processo bastante geral: qualquer substantivo simples e semanticamente adequado pode servir de base para a derivação de um verbo benefactivo. Uma nominalização de objeto baseada em um verbo benefactivo refere-se ao recipiente (real: $n$-kewei-ntə 'aquele a quem alguém dá um anzol', 'aquele que recebe um anzol de alguém'; potencial: ti-kewei-ntə-en 'aquele a quem se pode/deve dar anzóis', 'aquele que pode/deve receber anzóis') e pode ser utilizada como 'oração' relativa (5a). Participantes periféricos não-dativos ocorrem, em geral, como argumentos de posposições (5b); como a eles não corresponde nenhum processo análogo à verbalização benefactiva com o sufixo -ntə, não há nenhuma nominalização que se possa usar para 'relativizá-los'. Assim, a única solução possível é a coordenação de orações independentes (5c). A mesma situação é válida para possuidores (5d): como não há nominalizações que se refiram a possuidores, os falantes se vêem obrigados a usarem orações coordenadas (5e).

(5) 'Relativização' de participantes periféricos.

a. ampo nai, karaiwa, pihko i-n-kanawa-ntə-hpə ?

onde 3.cop homem 1.irmão 3-P.RE-canoa-BEN.VZR-PAS

'Onde está o branco a quem meu irmão deu uma canoa?'

('Onde está o branco, aquele que meu irmão "canoou" = proveu de canoa?')

b. wəri pə t-əturu

mulher sobre 1s-falar.PST

'Eu falei sobre a mulher.' c. wəri n-e:-jan, i-pə t-əturu

mulher 3s-vir-PRES 3-sobre 1s-falar.PAs

'A mulher sobre a qual eu falei está vindo.'

(= 'A mulher está vindo, eu falei sobre ela.' )

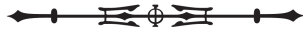

109 
d. wəri i-maja

mulher 3-faca

'a faca da mulher' e. wəri n-eł-jan, i-maja wi-ri

mulher 3s-vir-PRES 3-faca 1A-fazer.PAs

'A mulher cuja faca eu fiz está vindo.'

(='A mulher está vindo, eu fiz a faca dela.' )

Nominalizações circunstanciais com -to(po), (1e) e (1h), podem ter sentido instrumental, como em (6). Obtémse, em tais casos, algo semelhante, em sentido, a uma oração relativa de instrumento ("... com o qual....").

(6) 'Relativização' de instrumento.
ampo nai terehpo:ni, ə-wəturu-topo-mpə ?
onde 3.cop telefone 2-falar-CIRC-PAS
'Onde está o microfone com o qual você falou?'
('Onde está o microfone, instrumento para você falar?').

Como a aposição não é um fenômeno obrigatório, verbos nominalizados podem ocorrer, por si sós, com o sentido de 'orações' relativas sem antecedentes; recomenda-se a comparação entre os exemplos (2) e (7).

(7) 'Relativas' sem antecendentes.

a. ampo nai, [kaikui i-tu:ka-ne-mpə] ?

onde 3.cop cachorro 3-bater-A.RE-NPAS

'Onde está o que bateu no cachorro?'

b. a:no nai, ərka-ton ?

qual 3.COP morder-A.POT

'Qual é o que morde?'

c. [pahko i-n-tuika-hpə] ə-wa:rə ?

1.pai 3-P.RE-bater-NPAS 2-conhecido

'Você conhece (aquele) em que meu pai bateu?'

d. serə nai, t-əna-sen

DEM 3.COP P.POT-COmer-P.POT

'Este/Isto é o que se come (= que se pode comer; comestível.)'

e. n-e:-jan epi-keti-mpə

3s-vir-PRES tomar.banho-S.RE-NPAS

'O que tomou banho está vindo.'

f. ampo nai, ə-wərnih-topo-mpə ?

onde 3.COP 2-dormir-CIRC-NPAS

'Onde fica (o lugar) em que você dormiu (=o seu lugar de dormir)?.'

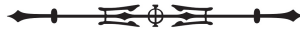


Advérbios/adjetivos, que formam uma única classe, podem também ser nominalizados. A forma resultante refere-se a uma entidade caracterizada pela qualidade descrita no termo original, por exemplo, kure 'bom, bonito', kura-no 'algo, alguém bom, bonito'. Essa forma nominalizada pode ser utilizada de modo equivalente a uma oração relativa, (8a) e (8b). Posposições (locuções pospositivas) têm o mesmo comportamento e usam os mesmos sufixos nominalizadores que os advérbios/adjetivos: pakoro 'casa' + tao 'dentro' $\rightarrow$ pakoro tao 'dentro da casa', do qual se deriva pakoro tao-n 'algo, alguém que está, mora dentro da casa'. Estas nominalizações também têm usos equivalentes a orações relativas, conforme se verifica em (8c) e (8d).

(8) Advérbios/adjetivos e posposições nominalizadas.

a. wəri, kawə-no, w-ene mulher alto-NZR 1A-ver:PAS 'Eu vi a/uma mulher alta.' b. wəri w-ene, kawə-no mulher 1A-ver.PAS alto-NZR 'Eu vi a/uma mulher alta.'

c. karaiwa, Makapa po-n, n-əturu-jan não.índio Macapá LOC-NZR 3s-falar-PRES 'O (homem) branco, macapaense (=que mora/está em Macapá), está falando.'

\section{d. karaiwa n-əturu-jan, Makapa po-n}

não.índio 3s-falar-PRES Macapá LOC-NZR

'O (homem) branco, macapaense (=que mora/está em Macapá), está falando.'

Deve-se acrescentar que a única maneira de 'modificar' um substantivo com um adjetivo em Tiriyó (e nas línguas Karíb até agora descritas) é exatamente a que se vê em (5a) e (5b): um adjetivo/advérbio nominalizado é colocado em aposição ao substantivo a ser modificado. Não há, conseqüentemente, diferença entre 'a mulher que é alta' e 'a mulher alta'; ambos são 'a mulher, a alta'. 'Adjetivos' monomorfêmicos ocorrem como complementos da cópula, ou então como modificadores de verbos; por esta razão, é freqüente entre os especialistas em línguas Karíb o uso do termo 'advérbio' para designar esta classe de palavras, apesar da existência de membros com significados como 'bonito', 'doce', 'alto' etc., tipicamente associados com adjetivos (MEIRA, 1999, 2003).

Nominalizações não são usadas só em orações relativas; elas aparecem também em subordinadas adverbiais, ou seja, como parte de sintagmas adverbiais, postos entre colchetes, (9a) e (9b). Assim, não se pode dizer que haja em Tiriyó formas específicas para a relativização.

(9) Nominalizações usadas adverbialmente.

a. sen wi-ri, [ə-n-ene me]

isto 1A-fazer.PAS 2-P.RE-ver ESS

'Eu fiz isto, para você ver.' (lit. 'como a sua coisa vista.')

b. məe w-ene-ne, [apəh-to me] ər-ja ə-njo me

este 1A-trazer-PAS 3.pegar-CIRC.NZR ESS 2-A 2-marido ESS

'Eu trouxe este (rapaz) para que você o pegasse como marido.'

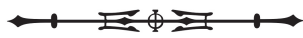




\section{NOMINALIZAÇÕES E RELATIVAS EM OUTRAS ĹNGUAS KARÍB}

Nesta seção, serão consideradas outras línguas da familia Karíb, sobre as quais se afirma na literatura que verbos nominalizados são, como em Tiriyó, o único meio de produção de orações relativas. O mecanismo é, em geral, análogo ao descrito na seção anterior para o Tiriyó, e os morfemas em questão são, via de regra, cognatos.

O ponto de partida será o Hixkaryana, em cujos dados disponíveis há exemplos de relativas baseadas em formas nominalizadas refentes a A, (10a) e (10b); P, (10c); e S (10d) e (10e). Observam-se casos de formas nominalizadas isoladas ('relativas sem antecedentes', (10b) e (10e)), bem como em aposição a substantivos ('relativas com antecedentes', (10a)).

(10) Hixkaryana (DERBYSHIRE, 1965, 1979, 1985).

a. n-omok-no harha $\int o \phi \mathrm{r}^{\mathrm{j}} \mathrm{e}, \quad \mathrm{k}$-anihnoh-ne-nhi-jamo 3s-vir-PAS de.novo preguiça.sp 1+2-destruir-A.RE-PAS-COL 'A preguiça que nos estava destruindo voltou.'

b. Manawsi hona Waraka nak-ne u-hutwe-he Manaus DIR Waraka enviar-A.RE 1A-saber-PRES 'Eu sei quem está mandando Waraka para Manaus.'

c. Manawsi hona Waraka ni-nak-ji-ri u-hutwe-he Manaus DIR Waraka P.RE-enviar-NZR-POS 1A-saber-PRES 'Eu sei quem Waraka está mandando para Manaus.'

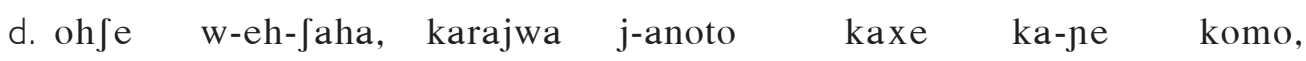
bem 1s-COP-PRES não.índio LG-servidor porque dizer-S.RE COL

n-os-onkuhte-t the

3S-DETR-enganar-PRES.COL

'Os que dizem "estou bem, trabalho para um branco", enganam-se.'

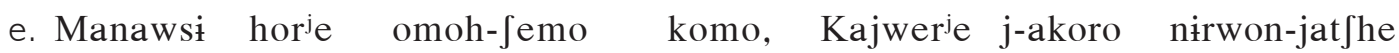
Manaus ABL Come-S.RE.COL COL Kajwer ${ }^{j}$ e LIG-COM 3s-falar-PRES.COL 'Os que vieram de Manaus estão falando com Kajwerie.'

Nos dados Waiwai, vê-se a mesma situação: nominalização de P (11a), A (11b) e de circunstante (11c), com antecedente aposto, (11a) e (11c) e sem antecendente aposto (11b). Note que dada a ambigüidade do nominalizador de circunstância -toфo, a 'oração relativa' em (11c) pode também ser interpretada como indicação de propósito: compara-se com o cognato Tiriyó -to(po) em (1e), (1h), (2f), (6).

(11) Waiwai (HAWKINS, 1998)

a. n-eske-si tak jawaka i-johto- $\int a \phi u$

3A-cortar-PRES agora machado 3-amolar-P.RE

'O machado que foi amolado corta (bem) agora.' (= não está mais cego) 
b. mija to-tfow marari j-ama-je komo

longe 3s.ir-PAS.COL rOça LG-COrtar-A.RE COL

'Os que cortaram (=abriram) a roça foram para longe.'

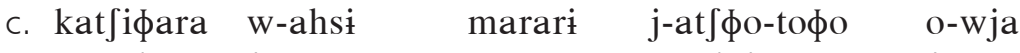

terçado 1A-pegar.PAS roça LG-abrir-CIRC 1-A

'Eu peguei o terçado com o qual vou abrir a roça.'; tb.: 'para abrir roça'

(= 'Eu peguei o terçado, instrumento de cortar a roça por mim.' )

Em Apalaí, os exemplos de relativas são pouco numerosos. Vê-se um caso de nominalização referente a P (12a), a qual está em aposição ao termo antecedente mokiro, um pronome demonstrativo animado. Em (12b), observa-se o uso de substantivos em aposição, kanawa 'canoa', zakare 'jacaré' e konõto '(algo) grande'. Nos dois exemplos, trata-se fundamentalmente do mesmo fenômeno.

(12) Apalaí (KOEHN, S.; KOEHN, E., 1986)

a. ku-akuo?-ko tam, ti-ka-se mokiro, kuto n-akuoty-Ppiri 1A2P-passar-IMPER avô PAS-dizer-PAS DEM rã P.RE-passar-NPAS ' "Leve-me para o outro lado (do rio), vovô", disse aquele, o qual a rã havia trazido (para este lado do rio).'

b. mame kanawa aro-ko repe zakare konõto rokene então canoa trazer-PAs em.vão jacaré grande somente 'Então, em vão, ele trouxe a canoa (que era) um jacaré grande.'

Em Makushi, encontram-se, desempenhando o papel de 'orações' relativas, exemplos de formas nominalizadas de A (13a), P (13b, c), S (13d) e de circunstante (13d). Em (13d), há uma 'relativa sem antecedente'; e em (13a) e (13c), há 'relativas com antecedentes', isto é, aposição entre formas nominalizadas e substantivos.

(13) Makushi (ABBOTT, 1991).

a. surara-jami era?ma-nenan witi-?pi Manaus pona soldado-COL ver-A.RE.COL ir-PAS Manaus DIR 'Os soldados, os que vigiaram (= olharam algo), foram para Manaus.'

b. u-n-era?ma-ipi pemonkon ekaremeki-u-ja siriri a-pi? 1-P.RE-ver-PAS pessoa contar-1-ERG PRT 2-para

'Eu vou contar a você sobre o homem que eu vi.'

C. miriri t-ena?-sen yapi?si-Ppi-i-ja

DEM P.POT-COmer-P.POT receber-PAS-3-ERG

'(Ela) recebeu este/isto que se come.' (= 'que se pode comer, que é comestível.')

d. mikkiri j-arakkiri asa-koi pepin uri

DEM LIG-COM andar-S.RE NEG 1

'Eu não sou o que anda com aquele (lá).'

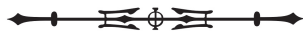




\section{RELATIVAS NÃO-NOMINALIZADAS}

Além do padrão normal de 'nominalizações relativas', descrito nas duas seções anteriores, há, em algumas línguas, partículas relativizadoras que podem ser usadas para transformar uma oração normal, com verbo finito, em oração relativa. Trata-se de um fenômeno relativamente raro na família, documentado por enquanto em apenas quatro línguas: Panare (GILDEA, 1989), Ikpeng (PACHECO, 2001), Tamanaku (GIL], 1965), e Yukpa (MEIRA, notas de campo). É possível que haja outros casos entre as línguas menos conhecidas (WaimiriAtroari, Yawarana, Mapoyo, De'kwana etc.)

Em Panare, Gildea (1989) descreve um sistema de sufixos relativizadores, -nə? para antecedentes animados, -sin e -mon - $n$ para antecedentes inanimados, cujas propriedades distribucionais servem de base para a distinção de três tipos de orações relativas. $\bigcirc$ primeiro tem todas as propriedades de uma oração finita normal, enquanto que os outros dois são menos finitos ${ }^{3}$. Discutir-se-á aqui apenas o primeiro tipo (finito) com antecedente animado, pois os casos de antecedentes inanimados são idênticos, diferenciando-se apenas pelo sufixo relativizador.

Em (14), vêem-sê alguns exemplos de orações relativas totalmente finitas (entre colchetes). A partir de uma oração normal (14a), pode-se formar uma relativa com antecedente animado através do sufixo -nə? (14b). Note-se que, como no caso das relativas nominalizadas, o termo antecedente parece estar em aposição (e logo externo) à relativa: apo? 'homem', pode não ocorrer (14c) e também pode trocar de lugar com tijaa-nə? (14d). Em orações transitivas, A e P distinguem-se pelo comportamento do prefixo de terceira pessoa, o qual desaparece quando o termo anterior ao verbo é o P (o que acarreta também o deslocamento do acento, (14e) e (14f) $)^{4}$. Em orações relativas, este fato é suficiente para identificar a função do antecedente (que está ausente): se o termo restante é P, o antecedente era A (14f; o prefixo ni- '3AP' desaparece); se o termo restante é A, o antecedente era P (14e; o prefixo ni- '3AP' não desaparece). Se o antecedente desempenhar outra função na relativa, o seu papel é retomado por um marcador de terceira pessoa. Esta situação é geralmente chamada estratégia do 'pronome resuntivo' (do inglês resumptive pronoun), um termo, neste caso, infeliz, já que o elemento que retoma o antecedente não é um pronome, mas sim um prefixo de pessoa. De qualquer maneira, esta é a estratégia usada com antecedentes que, na oração relativa, têm função de dativo (14g), circunstante (14h) ou possuidor (14i).

(14) Orações relativas finitas em Panare (GILDEA, 1989).
a. ti-ja? apo?
3s.ir-PAS homem
b. n-u?púma-ja? apo?
[ti-jai-nə?]
'O homem foi embora.'

3s-cair-PAS homem 3 s.ir-PAS-REL
'O homem que foi embora caiu.'

3 Gildea (1989), sem mencionar exemplos, afirma que nominalizações são também usadas como equivalentes a orações relativas, o que adiciona ao leque de possibilidades um quarto tipo não-finito.

4 Uma descrição detalhada da marcação de pessoa em verbos transitivos finitos em Panare vai além do escopo deste trabalho. Tratase de um sistema complexo (como é freqüentemente o caso para línguas Karíb), com prefixos que indicam várias combinações de $A$ e $\mathrm{O}$, e que, em algumas línguas, também definem dois grupos de verbos intransitivos (MEIRA, 2000). Para o presente trabalho, basta afirmar que a marcação de pessoa em orações relativas finitas e em orações principais é idêntica, inclusive no que diz respeito ao desparecimento do prefixo $n(i)-$ '3AP'.

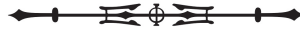


c. n-uPpúma-ja? [ti-ja:-nə?] 3s-Cair-PAS 3s.ir-PAS-REL '(Aquele) que foi embora caiu.' d. n-u?púma-ja? [ti-ja:-nə?] apo?

3s-Cair-PAS 3s.ir-PAS-REL homem

'O homem que foi embora caiu.'

e. ti-ja? kən [Paco ni-petjúma-ja:-nə?]

3s.ir-PAS DEM PaCo 3AP-bater-PAS-REL

'Aquele em que Paco bateu foi embora.'

f. ti-ja? kən [Pako pétjuma-ja:-nə?]

3s.ir-PAS DEM Paco bater-PAS-REL

'Aquele que bateu em Paco foi embora.'

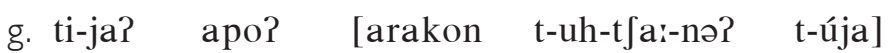

3s.ir-PAS homem macaco 1A-dar-PAS-REL 3-DAT

'O homem a quem dei o macaco foi embora.' (=...que dei o macaco para ele)

h. ti-ja? apo? [j-oromaepún-jai-nə? tji-pə Toman úja]

3s.ir-PAS homem 1s-falar-PAS-REL 3-sobre Tomás DAT

'O homem sobre quem falei a Tomás saiu.' (=...que falei a Tomás sobre ele)

i. ti-ja? winkî? [ji-mata-n t-amani-jai-nə?]

3s.ir-PAS mulher 3-ombro-POS 1A-consertar-PAS-REL

'A mulher cujo ombro consertei foi embora.' (= ...que consertei o ombro dela)

Em Tamanaku, uma língua extinta sobre a qual há bastante documentação (GILI, 1965), parece ter havido um sistema semelhante ao do Panare. Segundo a análise de Gildea e Meira, baseada no material de Gilij, há duas partículas relativizadoras, net $f i$ para antecedentes animados e ri para antecedentes inanimados. Notese que net $\int i$ é um provável cognato do Panare nə? descrito no parágrafo anterior. Esta semelhança sugere que a estrutura das orações relativas (as 'estratégias de relativização') do Tamanaku seja similar à do Panare; contudo, como todos os exemplos remanescentes de orações relativas Tamanaku (listados em 15) envolvem verbos intransitivos, não há como verificar essa possibilidade (mas veja-se 15e, onde it-awe parece desempenhar a função de 'pronome resuntivo', como seria de se esperar em Panare). Nos exemplos (15a) e (15b), observa-se o uso de net fi e ri após verbos intransitivos. Quando orações relativas ocorrem sem verbos (em geral, predicados nominais), as partículas relativas recebem uma silaba extra ma(i), tornando-se manet $\int i$ e mairi, exemplos de (15c) até $(15 \mathrm{e})^{5}$.

(15) Orações relativas finitas em Tamanaku (GILJ, 1965; análise de GILDEA e MEIRA)

\begin{tabular}{|c|c|c|c|}
\hline $\begin{array}{l}\text { a. t } \text { tonkai?pe } \\
\text { qual }\end{array}$ & 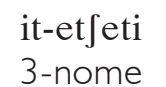 & $\begin{array}{l}\text { pare } \\
\text { padre }\end{array}$ & $\begin{array}{c}{[\mathrm{n}-\mathrm{epu}-\mathrm{i}} \\
\text { 3s-vir-PAS }\end{array}$ \\
\hline
\end{tabular}

'Qual é o nome do padre que veio?'

5 Não é impossível que essa silaba ma seja, na verdade, uma forma da cópula; há possíveis cognatos em outras línguas da familia, inclusive em Panare (GILDEA, 1989).

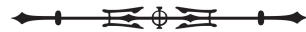


$\begin{array}{llclll}\text { b. tekape } & \text { maria } & \text { [tana } & \text { re } & \text { n-aci-i } & \text { ri] ? } \\ \text { onde } & \text { faca } & \text { aqui } & \text { ENF } & \text { 3s-COP-PAS } & \text { PRT.REL }\end{array}$

'Onde está a faca que estava aqui?'

c. pare [kaprut po manet]i] patkur pe

padre Cabruta LOC PRT.REL bom ESS

'O padre que está em Cabruta é bom.'

d. t Jonpe more [taremu?ne mairi] ?

que DEM white PRT.REL

'Que coisa é essa que é / está ficando branca?'

e. taure re pata jaka, taro uja, [kikemo amenare it-awe mairi]

outro ENF aldeia DIR dizer 1.A $1+2$ agora 3-LOC PRT.REL

'Para outro lugar, eu disse, no qual agora (estamos) (=vivemos, moramos).'

Em Ikpeng, Pachêco (2001) descreve, além de orações nominalizadas segundo o padrão da família - (16a) e (16f); compare-se (16a) com (2a), também orações relativas finitas, marcadas por duas partículas, pa wa e keni, que ocorrem juntas, (16c), (16d) e (16 f), ou separadas, (16b) e (16e). A função exata de cada partícula ainda não foi investigada. Há exemplos de orações relativas onde o antecedente é P, (16b) e (16c), S (16d) ou um circunstante (16e). Nesses casos, como em Panare, o antecedente está ausente se sua função na relativa é S ou P, (16b) e (16c), e é retomado por um prefixo de pessoa nos demais casos, (16d) e (16e). Não há exemplos onde o antecedente é, na relativa, um possuidor.

(16) Orações relativas em Ikpeng (PACHECO, 2001).

a. j-eney-li petkom [itereku erenmi-ni-npin]

1A-ver-PAS mulher galinha matar-A.RE-NPAS

'Eu vi a mulher que matou a galinha.'

b. petkom [enen-li pa Cilene keni] t-eru-li anat ajpi ina mulher 3AP.ver-PAS PRT.REL Cilene PRT.REL 3AP-dar-PAS milho menino DAT 'A mulher que Cilene viu deu milho ao menino.'

c. petkom arimton itereku [Cilene erenmi-nay pa keni] mulher 3AO.cozinhar galinha Cilene 3AO-matar-PRES PRT.REL PRT.REL 'A mulher vai cozinhar a galinha que a Cilene está matando.'

d. i-wari appi [aranme-nay pa keni] 1-amigo menino 3s.correr-PRES PRT.REL PRT.REL 'O garoto que está correndo é meu amigo.'

e. karajwa nen enu [i-ge j-etpu-li wa megu keni] faca DEM novo 3-com 1A-cortar-PAS PRT.REL melancia PRT.REL 'A faca com que eu cortei a melancia é nova.'

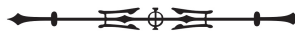


Em Yukpa, dados de campo recolhidos recentemente demonstram a existência de orações relativas finitas, marcadas pela partícula kat. Ao contrário dos casos anteriores, a partícula kat ocorre não no fim, mas no início da oração relativa. Os exemplos mostram casos de antecedentes que desempenham, na relativa, o papel de $S$ (17a), P (17b) e (17d), A (17c). A relativa pode ocorrer sem antecedente na oração principal (17d). Quanto a antecedentes em função de circunstante, os exemplos são menos claros. No exemplo (17e), um antecedente em função de objeto indireto (dativo) é indicado por uma partícula diferente, t $\int$ onaska, cujos usos ainda não foram investigados. Em (17f), o antecedente é, logicamente, objeto da posposição ekare 'sobre'; esperar-seia, seguindo-se o padrão das línguas acima examinadas, que o antecedente fosse retomado por uma forma de terceira pessoa de ekare, mas isso não ocorreu. Não se sabe se esta é a regra geral.

(17) Orações relativas finitas em Yukpa (MEIRA, notas de campo).

a. aw peru ekar=ja [kat patum=ne]

1 cachorro sobre=1. COP REL bonito=3. COP.PAS

'Eu estou (falando) sobre o cachorro que era bonito.'

b. ake worepa [kat aw s-esar $=\mathrm{po}=\mathrm{ja}] \quad$ patume $=\int \mathrm{e}=\mathrm{mak}$

DEM woman REL 1 3P-ver-PRES=1.AUX bonito $=E N F=3$. COP

'A mulher que eu estou vendo é muito bonita.'

c. ake worepa [kat aw j-esar $=\mathrm{po}=\mathrm{ja}] \quad$ patume $=\int \mathrm{e}=\mathrm{mak}$

DEM woman REL 1 1P-ver-PRES $=1$. AUX bonito $=E N F=3$. COP

'A mulher que me está vendo é muito bonita.'

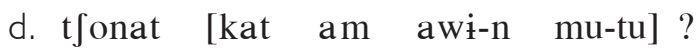

onde REL 2 1-DAT 2A-dar.PAS

'Onde está o que você me deu?'

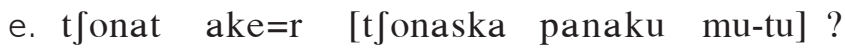

onde DEM=ENF REL? faca 2A-dar.PAS

'Onde está aquele a quem você deu a faca?'

f. ake $=\int$ peru [kat amo-n woneta] sa=ne siw

$\mathrm{DEM}=$ ? cachorro REL 2-DAT 1s.falar.PAS assim=3.COP.PAS branco

'O cachorro de que eu lhe falei era (assim) branco.'

Os exemplos seguintes, contudo, sugerem que a partícula kat não seja meramente um relativizador, mas talvez um marcador de subordinação mais geral. No exemplo (18a), kat funciona como elemento de ligação entre o adjetivo fape 'grande' e o substantivo por ele modificado, o que, em princípio, ainda é compatível com a função de relativizador ('o meu irmão que é maior'). Já nos exemplos (18b) e (18c), kat tem um sentido temporal 'quando' e em (18d), locativo 'onde' trata-se de uma resposta a perguntas do tipo "Onde você gosta de ficar?". O exemplo (18e), resposta a "Onde você mora?", parece ser similar a (18d), embora não se possa excluir a possibilidade de uma oração relativa com mato 'aqui' como antecedente ('aqui, que é Maracaibo'). Sem dúvida, os usos da partícula kat merecem uma investigação mais detalhada.

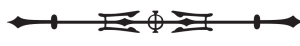


(18) Outros usos da partícula kat em Yukpa (MEIRA, notas de campo).
a. aw j-epujnu [kat Jape] 1 1-irmão REL? grande 'meu irmão maior'

c. [kat aw Jiriri iwo], n-akrime=ra

REL? 1 macaco bater.PAS 3s-correr.PAS=mas

'Quando eu bati no macaco, ele correu.'

\section{d. [kat aw j-imo] REL? 1 1-pai}

'Onde o meu pai está.' b. [kat aw jukpa $=\mathrm{p}=\mathrm{je}], \ldots$

REL? $1 \quad$ YukPa $=\mathrm{ESS}=1$. COP.PAS

'Quando eu era Yukpa, ...'

\section{CONCLUSÃO}

Como visto nas seções anteriores, a estratégia relativizadora mais comum na família Karíb envolve o uso de verbos nominalizados. Esta estratégia está sempre presente, mesmo nas línguas em que há orações relativas finitas com morfemas relativizadores. Além disso, os afixos nominalizadores são geralmente cognatos: Gildea (1998) reconstrói com sucesso os ancestrais Proto-Karíb de vários desses afixos. Por outro lado, os morfemas relativizadores descritos na seção 'Relativas não-nominalizadoras' não parecem ser cognatos (com a possível exceção do net $\int i$ Tamanaku e do -nə? Panare); é bastante verossímil que sejam resultados de inovações independentes. Conclui-se que o uso de verbos nominalizados é a estratégia relativizadora mais antiga, certamente já em vigor na época do Proto-Karíb.

A questão da análise dos verbos nominalizadas como 'orações' relativas demanda certa reflexão. Tais formas ocorrem com alguma freqüência nas línguas do mundo. Keenan (1985) menciona exemplos do turco e do tibetano. Por sua estrutura não ser igual à de uma oração declarativa normal, autores da escola gerativa não as consideram como orações. Mesmo dentro da escola tipológico-funcionalista, alguns autores não as tratam como orações, pelo menos não em todos os casos (WHALEY, 1997). Há, também, todo um leque de formas verbais mais ou menos finitas, mais ou menos 'nominalizadas' ou 'adjetivizadas', freqüentemente com usos relativos; aqui, fala-se com freqüência em 'gerúndios' ou 'particípios' (KEENAN, 1985). Mas os autores concordam, em geral, que a definição de oração relativa deve ser 'funcional' e não 'sintática'. Comrie (1989) sugere que se trata de uma 'estrutura que serve para restringir as possibilidades de referência de um certo núcleo nominal'. Givón (2001) propõe que 'uma oração relativa codifica um estado ou evento com um participante correferencial com o substantivo por ela modificado', funcionando como uma indicação para que o ouvinte possa identificar o referente em sua memória. Tais definições incluem, por exemplo, particípios como a forma -ing do inglês em usos com "passengers leaving on flight 738 should proceed to the departure lounge" ('os passageiros que partirão no vôo 738 devem dirigir-se ao portão de embarque'), ou até mesmo adjetivos como estudioso em 'o aluno estudioso consegue melhores resultados'. Em ambos os casos, há restrição do 'universo referencial' ou 'indicação para a identificação' do referente (nem todos os passageiros devem dirigir-se ao portão de embarque; nem todos os alunos conseguem bons resultados; note-se como o comparativo 'melhor' também sugere a existência de outros tipos de alunos além dos

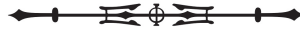


estudiosos). Essa relação é tornada explícita por Givón: adjetivos modificadores podem ser 'restritivos' ou 'não restritivos', exatamente como orações relativas, porque a sua função é, fundamentalmente, a mesma: restringir o universo de referência. Poder-se-ia chamar essa função de 'modificação'; como, entretanto, esse termo é freqüentemente usado em um sentido sintático, para representar um certo tipo de relação dentro de um sintagma nominal, prefere-se aqui o termo 'restrição'.

Há, em certas línguas, estruturas morfossintáticas específicas para codificar a restrição. Nas línguas européias, é freqüente a existência de uma posição para adjetivos modificadores dentro do sintagma nominal; há, também, marcas específicas para orações relativas, que as ligam aos substantivos que estas modificam. Contudo, nem toda função é codificada gramaticalmente; nem toda função tem um exponente gramatical (morfossintático) específico. Este parece ser o caso com respeito à restrição nas línguas Karíb mais típicas: não há nelas uma expressão morfossintática espeć́fica da restrição. Embora existam sintagmas nominais (envolvendo construções genitivas), estes não incluem 'modificadores'. Aparentemente, a simples 'ordem linear', a qual também serve para expressar outras funções pragmáticas (foco, tópico etc.), é também empregada para a restrição. De uma maneira bastante icônica, dois substantivos (ou sintagmas nominais) tenderão a ser entendidos como co-referenciais se estiverem suficientemente próximos, ou marcados da mesma maneira (por exemplo, com a mesma posposição), como nos exemplos (4). A esta situação, que é um tipo de parataxe, pode-se dar o nome de 'aposição', como já vinha sendo feito nas seções anteriores deste trabalho. Conseqüentemente, parece mais correto dizer, para as línguas Karíb mais conservadoras, que não há orações relativas: 'há aposições relativas', que podem ser compostas por nomes de qualquer tipo, inclusive verbos nominalizados. De fato, nota-se que nem sequer há adjetivos modificadores como uma classe à parte: as raízes que traduzem noções adjetivais ('novo', 'grande', 'sujo' etc.) formam uma única classe com as que traduzem noções adverbiais ('agora', 'aqui', 'bem' etc.) e só podem ser usadas para restringir se forem nominalizadas e usadas em uma aposição relativa, como é o caso para as demais classes (verbos, posposições; como nos exemplos em 8).

Nas línguas Karíb mais inovadoras, onde há morfemas específicos para marcar orações relativas (e estratégias típicas para identificar a relação com o antecedente, como gapping ou 'pronomes resuntivos'), a situação pode ser diferente. É possível que, nessas línguas, a restrição, como função, esteja-se gramaticalizando. Seria interessante verificar se essa possível gramaticalização estender-se-ia também aos adjetivos: haveria nessas línguas uma classe de palavras especializadas em modificar substantivos? Existiria uma posição específica para essas palavras dentro do sintagma nominal? Estes seriam tópicos fascinantes para futuras pesquisas.

\section{ABREVIATURAS}
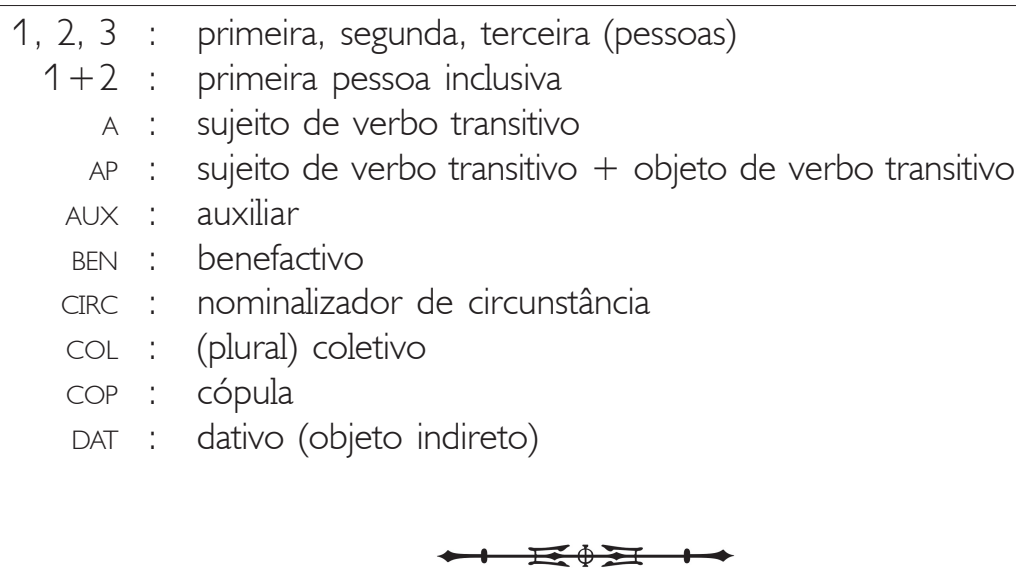


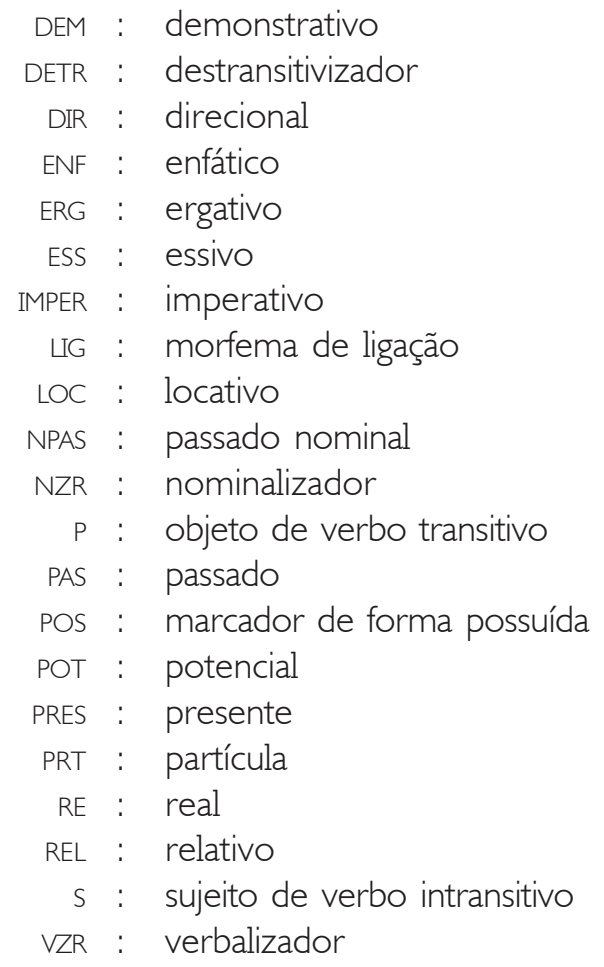

As abreviações podem ser unidas, com um ponto, se necessário. Tal como 3s : terceira pessoa, sujeito de verbo intransitivo; PRT.REL : partícula relativa.

\section{REFERÊNCIAS}

ABBOTT, M. 1991. Macushi. In: DerBYSHIRE, D. C.; PUllUM, G. K. (Ed.). Handbook of Amazonian Languages. Berlin, New York: Mouton de Gruyter. p. 24-160. v. 3.

COMRIE, B. 1981/1989. Language Universals and Linguistic Typology: syntax and Morphology. 2. ed. Chicago: University of Chicago Press. 264 p.

DERBYSHIRE, D. C. 1965. Textos Hixkaryâna. Belém: Museu Paraense Emílio Goeldi. (Publicações avulsas, n. 3).

DERBYSHIRE, D. C. 1979. Hixkaryana: lingua descriptive studies. v. 1. Amsterdã: North Holland. 199 p.

DERBYSHIRE, D. C. 1985. Hixkaryana and Linguistic Typology. Dallas: Summer Institute of Linguistics; Arlington: University of Texas. 263 p. DERBYSHIRE, D. C. 1999. Carib. In: DIXON, R. M. W.; AIKHENVALD, A. Y. (Ed.). The Amazonian Languages. Cambridge: Cambridge University Press. p. 23-64

GILDEA, S. 1989. Simple and Relative Clauses in Panare. Dissertação (Mestrado) - University of Oregon, Eugene, EUA.

GILDEA, S. 1998. On Reconstructing Grammar: Comparative Cariban Morphosyntax. Oxford: Oxford University Press. (Oxford Studies in Anthropological Linguistics, n. 18)

GILIJ, F. S. 1965 [1784]. Ensayo de Historia Americana. Tradução de A. Tovar. Caracas: Academia Nacional de la Historia. 3 v. Original de Saggio di Storia Americana, Roma.v. 4

GIVÓN, T. 2001. Syntax: an introduction. v. 2. Amsterdam: John Benjamins Publishing Company. v. 2.

HAWKINS, R. E. 1998. Wai Wai. In: DERBYSHIRE, D. C.; PULLUM, G. K. (Ed.). Handbook of Amazonian Languages. Berlin, New York: Mouton de Gruyter. p. 25-224. v. 4

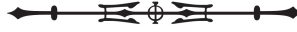


KEENAN, E. 1985. Relative clauses. In: SHOPEN, T. (Ed.). Language Typology and Syntactic Description: complex constructions. Cambridge: Cambridge University Press. v. 2.

KOEHN, S.; KOEHN, E. 1986. Apalaí. In: DERBYSHIRE, D. C.; PULLUM, G. K. (Ed.). Handbook of Amazonian Languages. Berlin, New York: Mouton de Gruyter. p. 33-127. v. 1.

MEIRA, S. 1999. A Grammar of Tiriyó. Tese (Doutorado) - Rice University, Texas, EUA.

MEIRA, S. 2000. The accidental intransitive split in the Cariban family. In: GILDEA, S. (Ed.). Reconstructing Grammar: comparative linguistics and grammaticalization. Amsterdam, Philadelphia: John Benjamins. p. 201-230. v. 43. Typological Studies in Language (TSL).

MEIRA, S. 2003. Mental state postpositions in Tiriyó and other Cariban languages. Linguistic Typology. No prelo.

PACHÊCO, F. B. 2001. Morfossintaxe do verbo ikpeng (Karíb). Tese (Doutorado) - Universidade de Campinas (UNICAMP), Instituto de Estudos da Linguagem (IEL).

RODRIGUES, A. I. 1986. Línguas brasileiras: para o conhecimento das línguas indígenas. São Paulo: Loyola. 126 p.

WHALEY, L. J. 1997. Introduction to Typology: the unity and diversity of language. Thousand Oaks, Londres, Nova Delhi: SAGE Publications. 321 p. 